\title{
PRIMARY ARTERITIS OF AORTA CAUSING RENAL ARTERY STENOSIS AND HYPERTENSION
}

BY

\author{
T. J. DANARAJ, H. O. WONG, AND M. A. THOMAS
}

From the Departments of Medicine and Pathology, University of Singapore

Received January 30, 1962

Early reports of patients suffering from primary arteritis of the aorta described the effects of inadequate blood supply to the brain, eyes, and upper limbs resulting from occlusion of the large branches of the aortic arch (Savory, 1856; Takayashu, 1908; Giffin, 1939; Lewis and Stokes, 1942). These observations were subsequently confirmed, and the condition, which occurred mainly in young women, was differentiated from other diseases such as syphilis, atherosclerosis, dissecting aneurysm, and congenital anomalies that affected the aortic arch to produce a similar clinical picture (Shimizu and Sano, 1951; Caccamise and Whitman, 1952; Skipper and Flint, 1952; Ross and McKusick, 1953; Ask-Upmark, 1954; Kalmansohn and Kalmansohn, 1957). Various names were given to the entity: pulseless disease (Shimizu and Sano, 1951), young female arteritis (Ross and McKusick, 1953), Takayashu's syndrome (Trias de Bes, Lucas, and Barcons, 1955), primary arteritis of the aortic arch (Barker and Edwards, 1955), obliterative brachiocephalic arteritis (Gibbons and King, 1957), and aortic arch arteritis (Koszewski, 1958). In patients who came to necropsy, a chronic non-specific inflammatory process was described affecting chiefly the arch of the aorta and its main branches at or close to their origin and resulting in occlusion of their lumen (Frövig and Löken, 1951). The peculiar anatomical site of the lesions explained the classical clinical picture.

In addition to the picture of brachiocephalic involvement, other associated features have been recorded. Loss of pulsation in one or both femoral arteries, in combination with signs of involvement of the aortic arch, has been reported in patients in whom the abdominal aorta was normally pulsatile: it was postulated that obstruction to the blood flow was present at the level of the iliac arteries (Gibbons and King, 1957; Danaraj and Wong, 1960). Hypertension in the lower limbs in contrast to brachial hypotension was noted by Giffin (1939) who suggested the designation "reversed coarctation." Similar observations were also made by Lewis and Stokes (1942), Skipper and Flint (1952), and Caldwell and Skipper (1961). The cause of hypertension was not known, but Lessof (1958) suggested that it could be of renal origin.

In an earlier paper (Danaraj and Wong, 1959), we reported the occurrence of hypertension in two children consequent on stenosis of the orifices of both renal arteries caused by localized arteritis of the abdominal aorta: the histological appearance of the aorta indicated that this was a variant of Takayashu's syndrome. The purpose of this paper is to report on a further nine patients, all of whom presented with hypertension and in whom there was necropsy or radiological evidence of disease of the aorta, with involvement not only of the renal arteries but of other branches as well. A study of this series gives support to the thesis that primary arteritis of the aorta may affect not only the arch alone (to produce Takayashu's syndrome) but any part of the aorta, the clinical picture depending on which segments and which branches are affected. Primary arteritis involving the abdominal aorta with renal artery obstruction produces the syndrome of Goldblatt hypertension, which may occur independently of or together with Takayashu's syndrome. 


\section{CASE REPORTS}

Case 1. A married Chinese woman, aged 21, was first seen on June 10, 1960, when she complained of severe headache and vomiting. Five days earlier, she had been admitted to a surgical unit with localized pain and tenderness in the right iliac fossa and an appendicectomy had been done: it was noted at the time that her blood pressure was raised. Questioning elicited that she had not been well for a year, having had attacks of breathlessness and palpitations especially on exertion, with swelling of the feet on one occasion. On examination, pulses were felt over the arteries of the limbs, being equal on both sides: pulsation of the carotid arteries was visible and forceful. The blood pressure reading in the upper limbs was 120/110 mm. $\mathrm{Hg}$, while in the lower limbs it was $155 / 130$ on the left side and $140 / 100 \mathrm{~mm}$. Hg on the right. The heart was enlarged, the apex beat being forceful and felt in the sixth left intercostal space $10 \mathrm{~cm}$. from the midsternal line. The second sound in the aortic area was accentuated and there was triple rhythm but no murmurs. The fundi appeared normal.

The blood hæmoglobin level was $13.3 \mathrm{~g}$. per $100 \mathrm{ml}$., and the white cell count 14,000 per c. mm. with a differential count of 90 per cent polymorphonuclear leucocytes, 6 per cent lymphocytes, and 4 per cent monocytes. The erythrocyte sedimentation rate (Westergren) was $33 \mathrm{~mm}$. in one hour. The specific gravity of the urine was normal, but on a few occasions there were increased numbers of red blood cells and pus cells on microscopical examination. The blood urea level was $15 \mathrm{mg}$. per $100 \mathrm{ml}$. and blood culture and Kahn test were negative. Radiological examination showed an enlarged heart with a prominent left border and normal lung fields. There was cardiographic evidence of left ventricular hypertrophy and strain.

Response to treatment with hypotensive drugs was not satisfactory. Fever of $100-101^{\circ} \mathrm{F} .\left(37 \cdot 8-38 \cdot 3^{\circ} \mathrm{C}\right.$.) was present on four different days. On June 26, it was not possible to feel the right femoral pulse, and

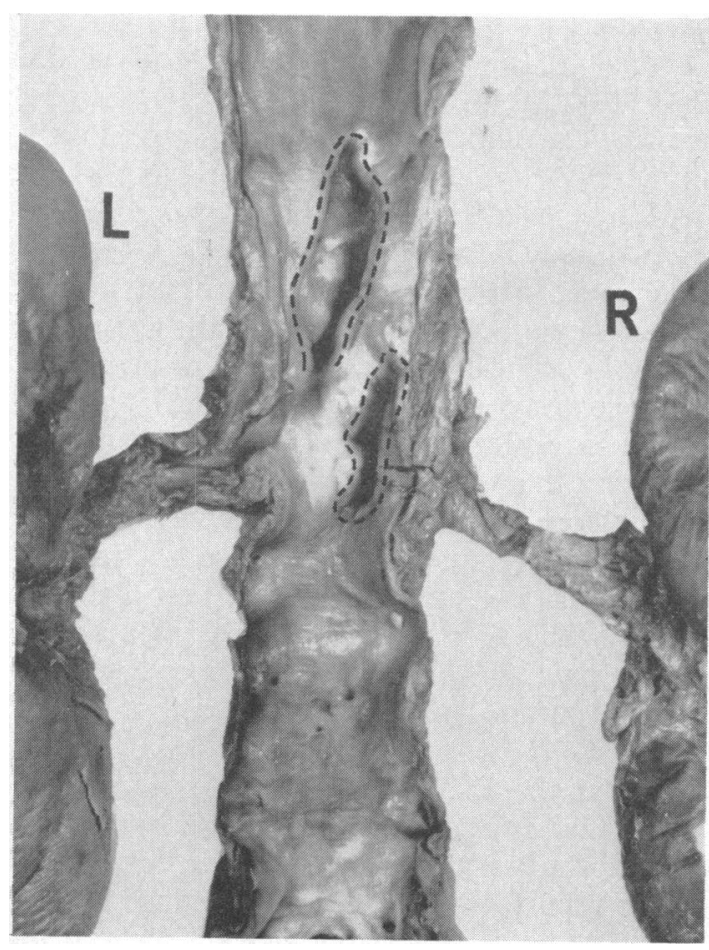

FiG. 1.-Case 1. Two elongated shallow depressions one below the other in wall of abdominal aorta. The coeliac and superior mesenteric artery orifices (not visible in picture) were identified in the wall of the upper one and found to be considerably narrowed: the orifice of the right renal artery identified in the wall of the lower one was occluded by a thrombus. The left renal artery orifice was unobstructed.

\section{four days later she died suddenly.}

Necropsy Findings. The heart (450 g.) was enlarged with hypertrophy of the left ventricle $(1 \cdot 7 \mathrm{~cm}$. thick), but was otherwise normal. The pulmonary arteries were not affected. On opening the aorta, three main areas of abnormality were seen. The first involved the entire circumference of the ascending aorta from its origin for a distance of $3 \mathrm{~cm}$. Over this area the intima was grossly thickened and pearly white and its surface irregular. The ostium of the left coronary artery was normal but the right one was considerably narrowed: distally the arteries were of normal calibre and their lining was smooth. The aorta felt thick, except where there were small shallow depressions on the intimal surface immediately above the aortic cusps. The second area extended for $6 \mathrm{~cm}$. of the abdominal aorta from just above the origin of the cœliac axis to the origins of the renal arteries and consisted of two longitudinal depressions, $4 \mathrm{~cm}$. by $2 \mathrm{~cm}$., and $3 \mathrm{~cm}$. by $1 \mathrm{~cm}$. respectively, situated one below the other (Fig. 1). The edges of the pouches were smooth, rounded and raised due to surrounding thickened intima. The orifices of the coeliac and superior mesenteric arteries, which were identified in the wall of the upper pouch, were considerably narrowed. The orifice of the right renal artery was identified in the wall of the lower pouch and found to be completely occluded by a thrombus which did not extend further into the lumen of the artery. The left renal artery was not obstructed. The third affected area showed considerable thickening of intima at the level of the bifurcation of the aorta. In addition there was a fusiform dilatation of the right common 


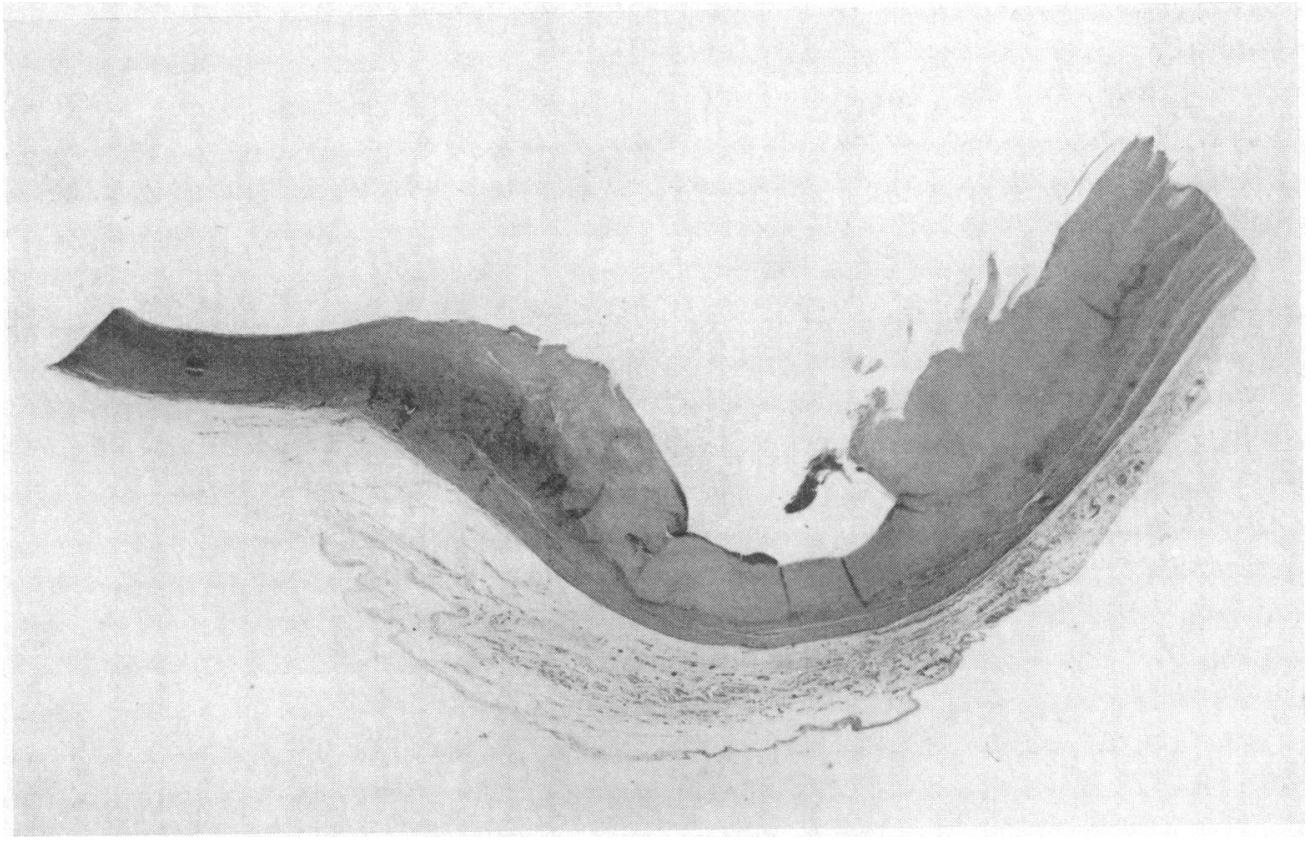

FIG. 2.-Case 1. Section of ascending aorta showing an area of localized dilatation with grossly thickened intima and thin partially destroyed media. (Verhoeff-Van Gieson: $\times 5$.)

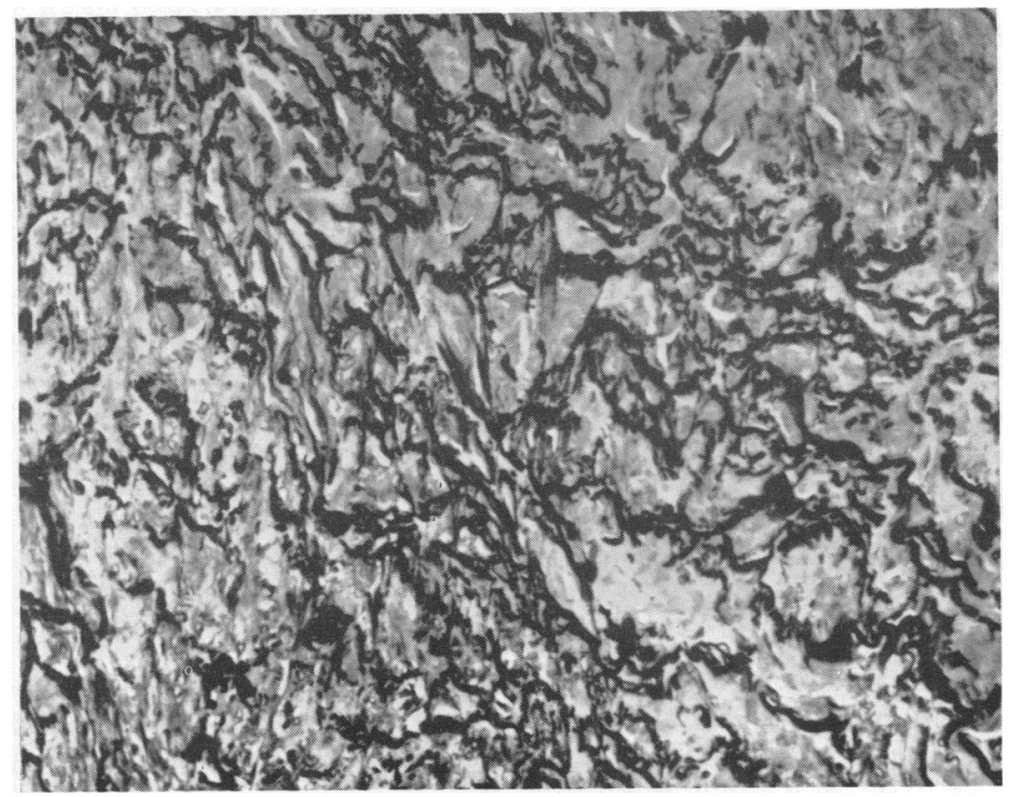

Fig. 3.-Case 1. Medial coat of ascending aorta showing patchy destruction of elastic fibres. (Verhoeff-Van Gieson: $\times 150$.) 
iliac artery which contained a thrombus that had occluded its lumen and extended into the internal iliac artery. The wall of the right common iliac artery at the site of the dilatation was calcified. Over the rest of the aorta, there were several scattered plaques of thickened intima varying in size from 0.5 to $1 \mathrm{~cm}$. These were found chiefly around the origins of the branches of the aortic arch, and the intercostal and lumbar arteries, but had not caused any narrowing of their orifices. The innominate, left common carotid, left subclavian, and cerebral arteries were normal. Both kidneys showed fœtal lobulation and the right, which was smaller than the left, had a small wedge-shaped area of recent infarction in its upper pole. The lungs were œdematous. Other organs were normal.

Histological Findings. There were no changes in the pericardium or the endocardium, but in the myocardium of both ventricles there were a few foci of degenerating and necrotic muscle fibres with fibrosis. Sections of the aorta taken from the three chief areas of abnormality showed severe inflammatory changes involving all three coats. The intima was greatly thickened due to proliferation of connective tissue which in the deeper layers had become hyalinized. There was widespread destruction of the underlying media resulting in disruption of the elastic fibres with replacement by fibrous tissue. Where localized depressions of the intima had been observed macroscopically, the elastic tissue was present only as a thin fragmentary line or was completely absent resulting in the formation of micro-aneurysms (Fig. 2 and 3). Ingrowth of new vessels surrounded by round cells had occurred in places where the medial destruction appeared to be at an early stage. Occasional giant cells were present. The adventitia was thickened. Many of the vasa vasorum showed considerable concentric endothelial proliferation resulting in narrowing or obliteration of their lumen (Fig. 4), and perivascular infiltrates of lymphocytes and plasma cells were

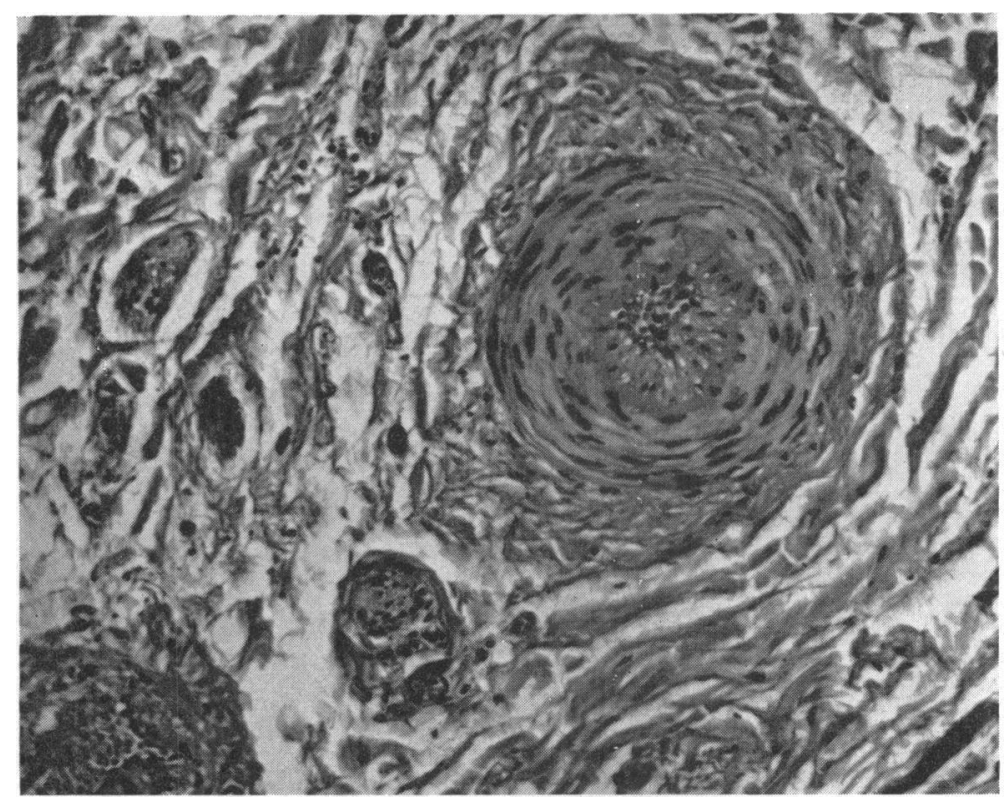

FIG. 4.-Case 1. Vasa vasorum in adventitia of the ascending aorta showing much endothelial proliferation with obstruction of lumen. (Hæmatoxylin and eosin: $\times 150$.)

present, except in one section of the abdominal aorta where an acute inflammatory exudate was seen surrounding a vessel. Sections of the small plaques scattered throughout the aorta revealed minor changes of intimal proliferation with small foci of medial degeneration. Sections from unaffected areas of the aorta were normal. The narrowing of the orifices of the right coronary, cœliac, superior mesenteric, and right renal arteries resulted from intimal changes in the aorta, the right renal artery also being occluded by a thrombus: sections of the arteries themselves showed no abnormality. The right common iliac artery showed changes similar to those seen in the aorta, but in addition a thrombus was present in the lumen of the artery 
and extensive calcification was seen in the deeper layers of the thickened intimal coat. No organisms were seen in any of the sections examined. In the right kidney an area of recent infarction was present in the upper pole; elsewhere there was periglomerular fibrosis with collections of lymphocytes in the interstitium and some tubular atrophy. The glomeruli were normal except for a few that were hyalinized. The intrarenal arteries showed no changes. The left kidney was normal.

Case 2. A Chinese man, aged 30, was brought to hospital in October 1960: a few hours earlier he had vomited suddenly, fallen down, and become unconscious. Before this, he had complained of headaches off and on for four years. The patient was unconscious and restless, moving the right limbs but not the left. All tendon reflexes were present and a Babinski's response was obtained on the right side. The neck was rigid and there was bilateral papillodema. The blood pressure in the right arm was $250 / 150 \mathrm{~mm}$. $\mathrm{Hg}$. Enlargement of the heart was not detected, the second sound in the aortic area was accentuated, and there were no murmurs. The cerebrospinal fluid was heavily blood stained. The patient died three hours after admission. A specimen of blood obtained post mortem gave a negative Kahn test.

Necropsy Findings. There was enlargement of the heart $(450 \mathrm{~g}$.) with hypertrophy of the left ventricle $(1.8 \mathrm{~cm}$. thick), but no other abnormality. There were several smooth, firm, raised plaques about $1 \mathrm{~cm}$. by $2 \mathrm{~cm}$. in size on the intima of the ascending aorta, aortic arch, and abdominal aorta. These plaques, most of which were situated in close proximity to the origins of the branches of the aorta, had partially narrowed the orifices of the right coronary and the left subclavian arteries. Just below the origin of the cœliac artery, there was a small circular depression of the aortic wall in which the orifice of the superior mesenteric artery was identified and found to be almost completely occluded by a thrombus which did not extend further into the artery (Fig. 5). The ostia of both renal arteries were considerably narrowed due to swelling and puckering of the adjacent intima; beyond their origins, the arteries were of normal calibre and showed no abnormality. The kidneys were normal in size and appearance. There was a large hæmatoma in the right cerebral hemisphere in the region of the basal ganglia. Apart from a few areas of atheroma, the cerebral arteries were normal. Other organs showed no pathological changes.

Histological Findings. The heart showed no abnormality apart from hyperplasia and hypertrophy of the muscle fibres of the left ventricle. Sections of the aorta taken through the areas with raised plaques revealed essentially the same pathological features as in Case 1. There was considerable thickening of the intima with varying degrees of destruction of the medial elastic coat. There were areas where the elastic fibres could be traced as a broad band up to the edge of the lesion only to break up into a few shreds and completely disappear with the formation of a micro-aneurysm (Fig. 6). The adventitia was

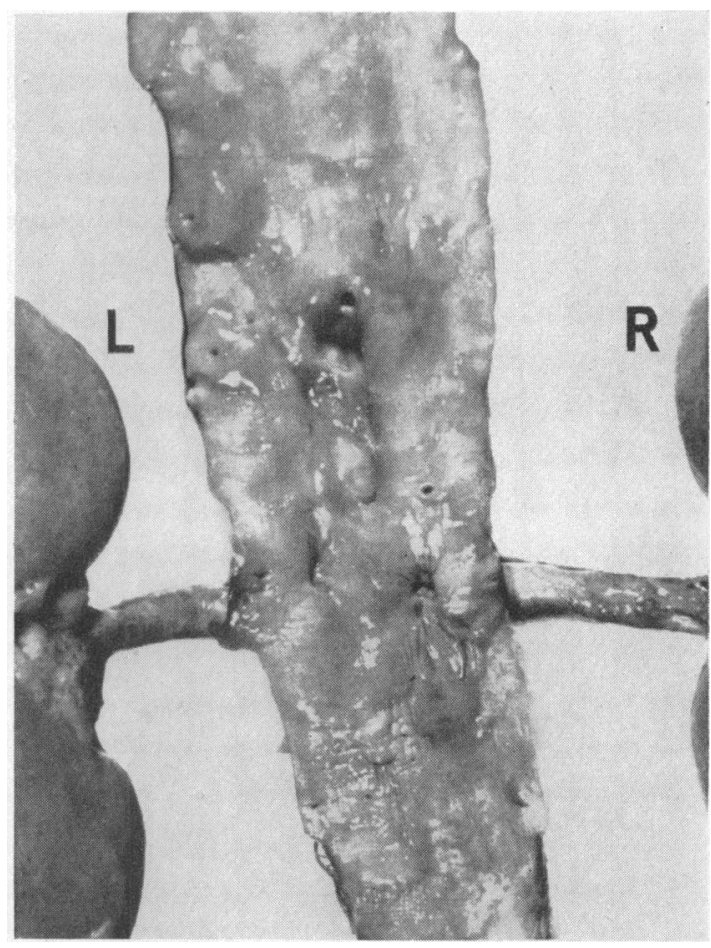

FIG. 5.-Case 2. Abdominal aorta showing shallow depression below opening of coliac artery and orifice of both renal arteries narrowed by adjacent thickened intima.

thickened and infiltrated with round cells, perivascular in distribution. Marked obliterative endarteritis of the vasa vasorum was present. In some places only the intima was thickened without any changes in the media and adventitia. In sections of the aorta taken near the origin of the innominate artery, there were moderately large foci of coagulative necrosis surrounded by round cells in the media (Fig. 7). The ostia of the renal arteries were narrowed by the thickened intima, and the orifice of the superior mesenteric artery was partially occluded by a thrombus adherent to a slightly thickened intima. Sections of these arteries and the other branches of the aorta showed no abnormality. In both kidneys there were a few areas where hyalinized glomeruli were seen; the intrarenal arterioles and smaller arteries showed moderate thickening of the walls. 


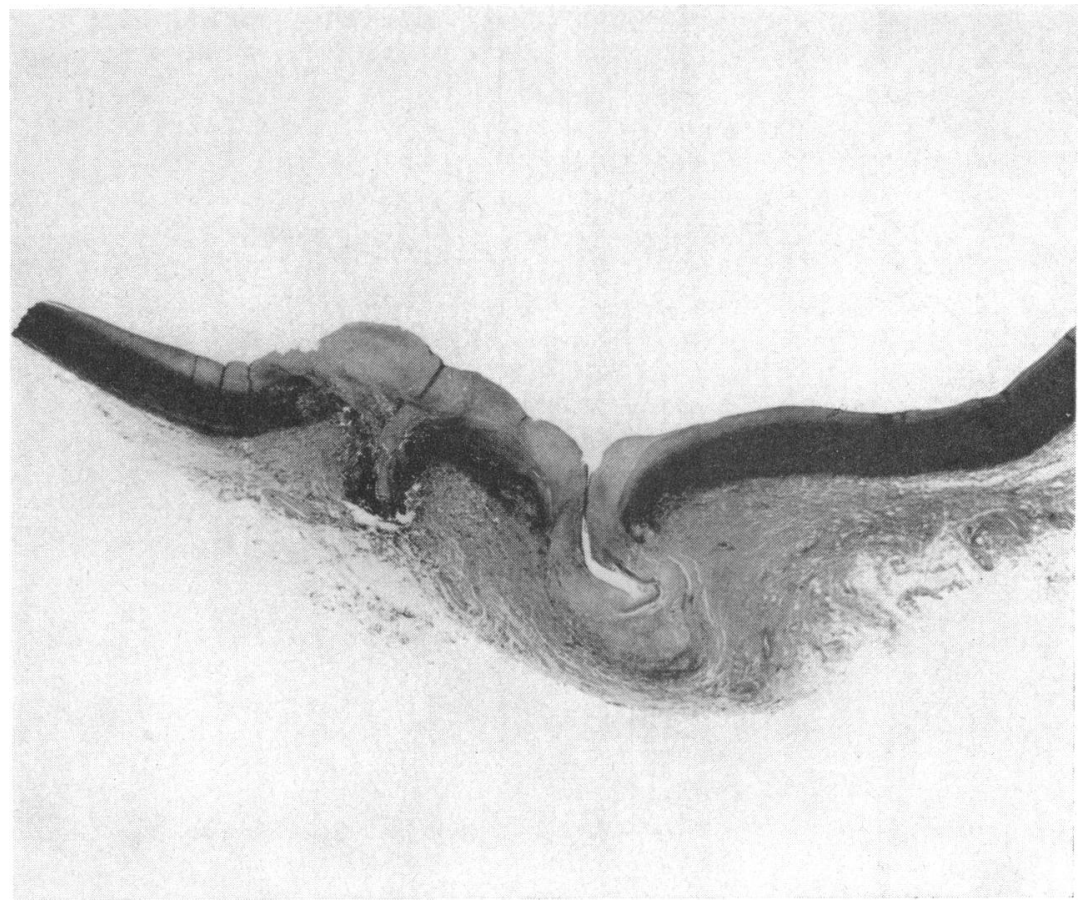

FIG. 6.-Case 2. Section of abdominal aorta showing micro-aneurysm at site where the media is deficient. Note thickened intima and adventitia. (Verhoeff-Van Gieson: $\times 5$.)

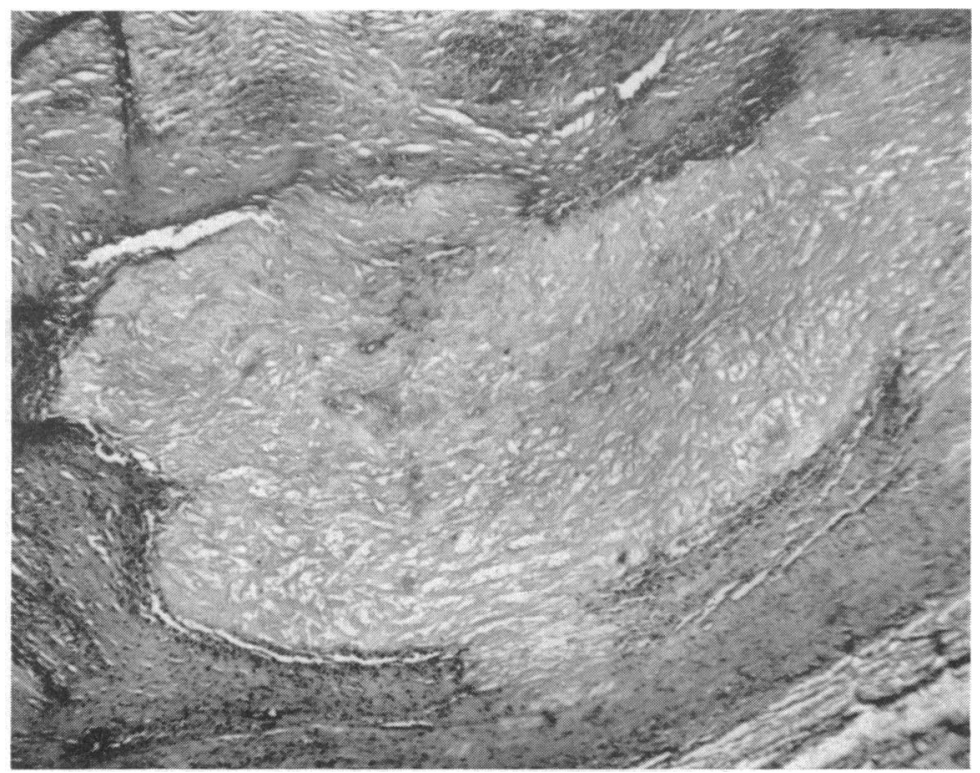

Fig. 7.-Case 2. An area of coagulative necrosis surrounded by round cells in media of aortic arch. (Hæmatoxylin and eosin: $\times 45$.) 
Case 3. A Chinese youth, aged 17, had been ill for two months with progressive breathlessness on exertion and cough with sputum which was sometimes blood stained. When he was admitted on November 22, 1961, he was in severe congestive cardiac failure. The heart was slightly enlarged and triple rhythm was present, but there were no significant murmurs. Crepitations were heard over the bases of both lungs and the liver was palpable three fingers' breadth below the costal margin. The blood pressure was 210/150 $\mathrm{mm}$. $\mathrm{Hg}$ and the retinal arteries were narrowed. Arterial pulsations in the limbs were present and equal on both sides; the right carotid artery was strongly pulsatile, but the left was barely felt and over its course a distinct systolic murmur was heard. The patient responded satisfactorily to treatment of the cardiac failure and with hypotensive drugs the blood pressure decreased to $160 / 110 \mathrm{~mm}$. $\mathrm{Hg}$. Laboratory investigations revealed a hæmoglobin level of $10.1 \mathrm{~g}$. $/ 100 \mathrm{ml}$., and normal total white cell and differential counts. The erythrocyte sedimentation rate was $34 \mathrm{~mm}$. in one hour. Lupus erythematosus cells were looked for in the peripheral blood, but none were found. The blood urea was $18 \mathrm{mg}$. $/ 100 \mathrm{ml}$.; blood culture and a Kahn test were negative. The results of other examinations, namely, a platelet count, bleeding time, clotting time, serum cholesterol content, electrophoretic analysis of serum proteins and serum electrolytes, were within normal limits. Urine examination showed no abnormality. There was electrocardiographic evidence of left ventricular hypertrophy, and a radiograph of the chest revealed an enlarged heart with congested lung fields. He developed cardiac failure again and died on December 18, 1961.

Necropsy Findings. Aortography revealed a normal aortic arch and the main branches were visible, but the calibre of the left common carotid artery was narrowed. The descending thoracic aorta showed a variable diameter with areas of narrowing and dilatation. The abdominal aorta and common iliac arteries were normal. The left renal artery was clearly seen but not the right. The superior mesenteric artery could be faintly made out, but the cœliac artery was not visible.

The heart ( $345 \mathrm{~g}$.) was enlarged due to hypertrophy of the left ventricle $(2 \mathrm{~cm}$. thick). On the anterior surface near the apex and on the posterior surface of the heart, a few areas of petechial hæmorrhages were seen: the rest of the heart showed no abnormality. Changes were noted in the aorta corresponding with the findings in the aortogram. The aorta was not uniform in size, the descending thoracic segment being irregularly dilated. The intima of the ascending aorta was smooth except for a small area of thickening just above the left coronary ostium. Flecks of intimal thickening were seen in the arch of the aorta and around the openings of the three great branches. The innominate artery, just before its division, was unevenly dilated and the intima at this site was thickened. The origin of the left common carotid artery was narrowed and its wall for a distance of $6 \mathrm{~cm}$. was uniformly thickened resulting in a considerable reduction of its lumen. From the origin of the left subclavian artery and ending abruptly at the origin of the cœliac artery, the intima was swollen, puckered, and thrown into irregular longitudinal folds: this was more marked in the lower $8 \mathrm{~cm}$. There was a deep pit in the upper portion of the descending thoracic aorta and below this an area of relatively normal looking intima. The ostium of the coliac artery was narrowed to a longitudinal slit by the surrounding swollen intima (Fig. 8). The aorta below this level was of normal calibre, its surface smooth except immediately above the orifice of the right renal artery where there was a circular plaque of thickened intima which extended into the first centimetre of the artery and reduced its lumen considerably. The left renal artery was unobstructed. The right kidney measured $10 \mathrm{~cm}$. by $6 \mathrm{~cm}$. by $3 \mathrm{~cm}$. and was smaller than the left which measured $12 \mathrm{~cm}$. by $7 \mathrm{~cm}$.

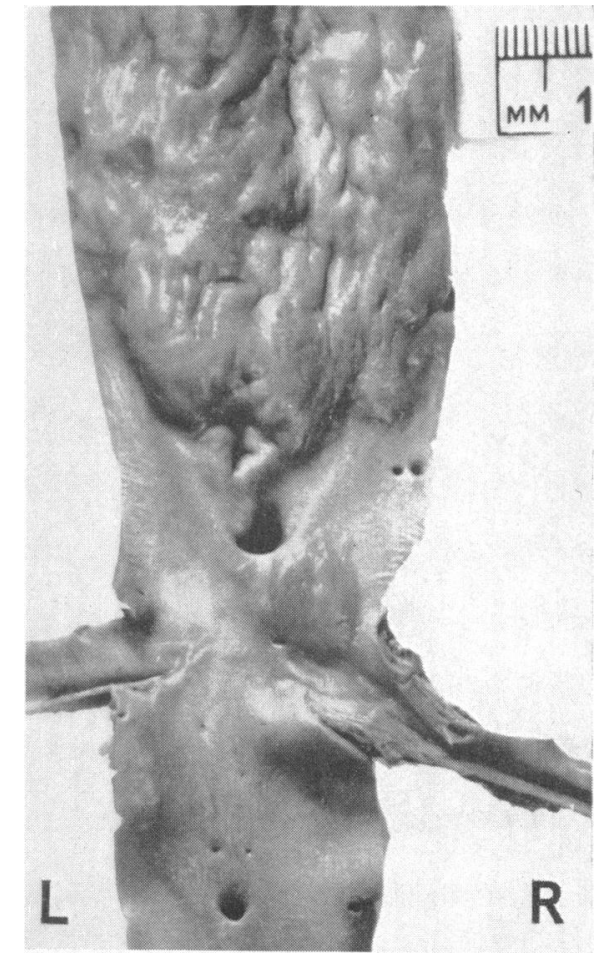

Fig. 8.-Case 3. Abdominal aorta showing swollen intima extending down to orifice of cœliac artery which is narrowed to a vertical slit. Immediately below and to the right of the orifice of the superior mesenteric artery there is a circular plaque of thickened intima which extends into the ostium and first centimetre of the right renal artery thereby narrowing its lumen. The left renal artery is not obstructed. 
by $4 \mathrm{~cm}$. The capsules of both kidneys stripped easily and the cut surfaces appeared normal. Other organs were congested but otherwise normal.

On microscopical examination, affected portions of the aorta and the innominate and left common carotid arteries revealed an extensive panarteritis similar to that described in the previous two cases. Sections of both kidneys showed no abnormality.

Case 4. A Chinese girl, aged 16, complained of breathlessness on exertion for three months. A few hours before admission on December 8, 1956, she became very breathless and had cough with frothy bloodstained sputum. She was found to be in severe congestive cardiac failure with a blood pressure of 160/110 $\mathrm{mm}$. Hg. The heart was slightly enlarged, but there were no significant murmurs. All peripheral pulses were palpable and equal. The fundi were normal. She responded satisfactorily to treatment of heart failure. The hæmoglobin was $12.6 \mathrm{~g} . / 100 \mathrm{ml}$. and total white cell and differential counts were normal. The erythrocyte sedimentation rate was $50 \mathrm{~mm}$. in one hour. The blood Kahn test was negative. Other blood examinations (as reported in the previous case) did not reveal any abnormality. Urine examination was normal. The electrocardiogram gave evidence of left ventricular hypertrophy, and on X-ray examination the heart was found to be slightly enlarged with a prominent left border. She was treated with hypotensive drugs, but response was not satisfactory. After about a year of observation it was noted that the left radial pulse was not as forceful as the right and that there was a difference in blood pressures: left arm 140/110 and right arm $220 / 150 \mathrm{~mm}$. Hg. A systolic bruit was now heard to the left of the umbilicus. Further investigations were then carried out.

Intravenous pyelography showed good excretion by both kidneys with the left kidney slightly smaller than the right: the calyces were of normal size. There was no dilatation or stricture of either ureter, but the calibre of the left was grossly irregular due to marginal indentations which were present almost the entire length of its course. Aortography revealed a normal aortic arch with good visualization of the innominate and left common carotid branches, but the left subclavian did not fill beyond $1 \mathrm{~cm}$. from its origin. The rest of the aorta was normal except that, about the level of the origin of the coeliac artery, the calibre of the abdominal aorta was considerably narrowed by a deep indentation on its left side; the aorta distal to this constriction was slightly dilated. The branches of the cœliac artery were clearly seen, but the superior mesenteric and left renal arteries were not. The right renal artery was slightly narrowed at its origin and dilated along the middle third of its course. The inferior mesenteric artery was hypertrophied with large left colic branches. In later films, small, tortuous, tightly coiled ureteric arteries were seen extending from the region of the left renal pedicle to below the level of the bifurcation of the aorta. Both kidneys were outlined, the left being slightly smaller than the right.

The patient has refused operation and the blood pressure has remained raised in spite of treatment with various hypotensive drugs. The left radial pulse is not palpable now and the abdominal bruit has become louder. Radiological examination in November 1961 shows further cardiac enlargement, and a curvilinear calcification of the abdominal aorta for a distance of $3.5 \mathrm{~cm}$. at the level of the first and second lumbar vertebral bodies: the left kidney is much smaller than the right.

Case 5. A Chinese girl, aged 15, was admitted to hospital in April 1954 for fits and was discovered to be suffering from hypertension. She was first seen by us in April 1957, when she complained of pain over the left shoulder and arm of two months' duration. There was a mass of firm matted lymph nodes in the region of the lower end of the left sternomastoid muscle and, along its length, several discrete nodes, one of which on biopsy showed only lymphoid hyperplasia. Blood pressure taken in the right arm was $150 / 110 \mathrm{~mm}$. $\mathrm{Hg}$. Pulses were not felt in the left upper limb. An electrocardiogram and radiograph of the chest were normal. She was admitted to hospital in December 1959 because the cervical nodes had become larger. Tuberculous lymphadenitis was diagnosed after a second biopsy and specific treatment was started. By April 1960, the nodes were no longer palpable, and she felt well. On re-examination no pulses could be felt in the left upper limb, while the blood pressure in the right arm was $180 / 115 \mathrm{~mm}$. $\mathrm{Hg}$. The heart was not enlarged and the fundi were normal.

The hæmoglobin level was $12.6 \mathrm{~g} . / 100 \mathrm{ml}$. and total white cell and differential counts were normal. The erythrocyte sedimentation rate was $14 \mathrm{~mm}$. in one hour. Urine examination was normal. The blood Kahn test was negative. Other examinations of the blood did not disclose any abnormality. Aortography showed a normal aortic arch with good filling of the innominate and left common carotid arteries, but the left subclavian artery was occluded one centimetre from its origin. The abdominal aortogram appeared normal and the right renal artery was faintly but clearly visible; the left one was not seen. The nephrogram showed a large right kidney, but a small left one.

Two days after nephrectomy, the blood pressure in the right arm had fallen to $140 / 90 \mathrm{~mm} . \mathrm{Hg}$ and it has 
remained at this level for the past year. In January 1961, the femoral arterial pulses felt weaker than previously, and a soft systolic bruit was heard in the midline just above the umbilicus. Retrograde femoral aortography was carried out. This revealed an abdominal aorta of normal calibre in its upper part, tapering to a narrowed segment at the level of the origin of the right renal artery, below which was a short post-stenotic dilatation with irregular walls: the (right) renal artery was unobstructed in its entire course.

The left kidney weighed $21 \mathrm{~g}$. Its upper two-thirds appeared normal, but the lower third was shrunken with marked cortical atrophy: a clear line of demarcation separated the two portions. Microscopical examination of the lower portion of the kidney showed diffuse fibrosis with cellular infiltration by lymphocytes and plasma cells in the interstitium. There was tubular atrophy and hyalinization of the glomeruli which were crowded together. Some of the tubules contained eosinophilic hyaline material. Marked intimal thickening of the arterioles with narrowing of the lumen was present. Similar changes were noted in the upper part of the kidney, but to a much lesser degree. The renal artery and its main branches at the hilum showed minimal intimal thickening, but there was no occlusion or narrowing of their lumen.

Case 6. A Chinese girl, aged 18, was seen in October 1958 for bancroftian filarial lymphangitis of both legs which responded to treatment with diethylcarbamazine. At that time it was noted that neither arterial pulsations nor blood pressure readings could be obtained in the upper limbs. She was admitted in January 1959 with breathlessness on exertion of one month's duration and subsequently developed acute pulmonary œdema while in hospital. The blood pressure reading in the lower limbs was $230 / 130 \mathrm{~mm}$. Hg. The patient was treated for cardiac failure, responded satisfactorily, and was discharged. On March 15, 1959 she developed headache, giddiness, blurring of vision, and fits, and was readmitted in a drowsy state. She was treated with hypotensive drugs and recovered consciousness. In July 1959 she was seen again. There were strong, visible pulsations of both carotid arteries. Radial, brachial, and axillary pulses were not felt and blood pressure readings were not obtained in either arm. Both femoral arteries were strongly pulsatile and the blood pressure recorded over each thigh was $230 / 130 \mathrm{~mm}$. $\mathrm{Hg}$. There was slight cardiac enlargement with an accentuated second sound in the aortic area, but no murmurs. The retinal arteries were narrowed.

The hæmoglobin level was $12.4 \mathrm{~g} . / 100 \mathrm{ml}$. and the total white cell and differential counts were normal. The erythrocyte sedimentation rate was $40 \mathrm{~mm}$. in one hour. The Kahn test was negative. A cardiogram showed left ventricular hypertrophy. On radiological examination of the chest, the heart was found to be slightly enlarged with a prominent left border; the lung fields were clear. Intravenous pyelography showed poor excretion on both sides with the right kidney smaller than the left. Aortography revealed a normal aortic arch with the innominate and left common carotid arteries arising from a common root. The right common carotid artery was well filled, but the right subclavian was not visible and its probable site of origin was represented by a slight irregularity of the right wall of the innominate artery; the left subclavian was visible only at its origin from the aortic arch. A large number of collateral vessels were seen in the neck. The lumen of the descending thoracic aorta was of uneven calibre with a definite constriction at the level of the 10th and 11th thoracic vertebræ; below this there was a fusiform dilatation of the upper half of the abdominal aorta with an irregular outline. The lower half of the abdominal aorta was relatively narrow but of even calibre. The proximal part of the right renal artery was dilated; it then narrowed abruptly to a constriction before dividing into its branches. There were two renal arteries on the left side, the upper one being narrowed at its origin. The nephrogram showed that the left kidney was much larger than the right. A right nephrectomy was done in December 1959, but the blood pressure did not return to normal levels. Response to treatment with hypotensive drugs was poor. One year later retrograde aortography was repeated when it was found that stenosis of the left upper renal artery was greater than previously.

The right kidney weighed $50 \mathrm{~g}$.: its capsule stripped easily revealing a faintly granular surface. There was a clear demarcation between medulla and cortex which was $0.5 \mathrm{~cm}$. in width. On microscopical examination the glomeruli were seen to be crowded together due to atrophy of the convoluted tubules: the glomerular tufts were not abnormal although many showed periglomerular fibrosis. A chronic inflammatory reaction, especially in the cortex, was a feature in all sections examined, lymphocytes and plasma cells being present either diffusely or in focal aggregates in the interstitial tissue. The intrarenal arteries and arterioles showed no changes. Except for some focal intimal thickening, the renal artery was normal.

Case 7. A Chinese girl, aged 15, was admitted in July 1959 complaining of breathlessness on exertion, palpitations, and cough with frothy, blood-tinged sputum. She was acutely ill and in congestive cardiac failure. The heart was not enlarged but the apex beat was forceful, and there was gallop rhythm, but no murmurs were heard. The blood pressure was $180 / 120 \mathrm{~mm}$. $\mathrm{Hg}$ in both arms and all peripheral pulses were felt. The retinal arteries were narrowed. She responded satisfactorily to treatment of the cardiac failure. Except for a hæmoglobin level of $11.8 \mathrm{~g}$. $/ 100 \mathrm{ml}$, a leucocytosis of $12,900 \mathrm{c} . \mathrm{mm}$. with a normal differential count, 
and an erythrocyte sedimentation rate of $23 \mathrm{~mm}$. in one hour, examinations of blood and urine revealed no abnormality. The Kahn test was negative. There was electrocardiographic evidence of left ventricular hypertrophy. Radiological examination of the chest showed a slight increase in cardiac size. Intravenous pyelography was normal. Aortography revealed a marked constriction of the left renal artery at its origin with a post-stenotic dilatation: the abdominal aorta and iliac arteries were clearly visible and of normal calibre. Twenty-four hours after left nephrectomy, the blood pressure became normal and has remained so during the past two years. Routine examination of the pulses in all limbs during her periodic visits revealed no abnormality until towards the end of the first year after operation when the femoral arterial pulses were noted to be weak, and on auscultation over the umbilicus a systolic murmur was heard. Aortography was repeated and revealed a narrowing of the abdominal aorta commencing immediately below the origin of the right renal artery and extending for a distance of $6 \mathrm{~cm}$. before a normal calibre was regained (Fig. 9).

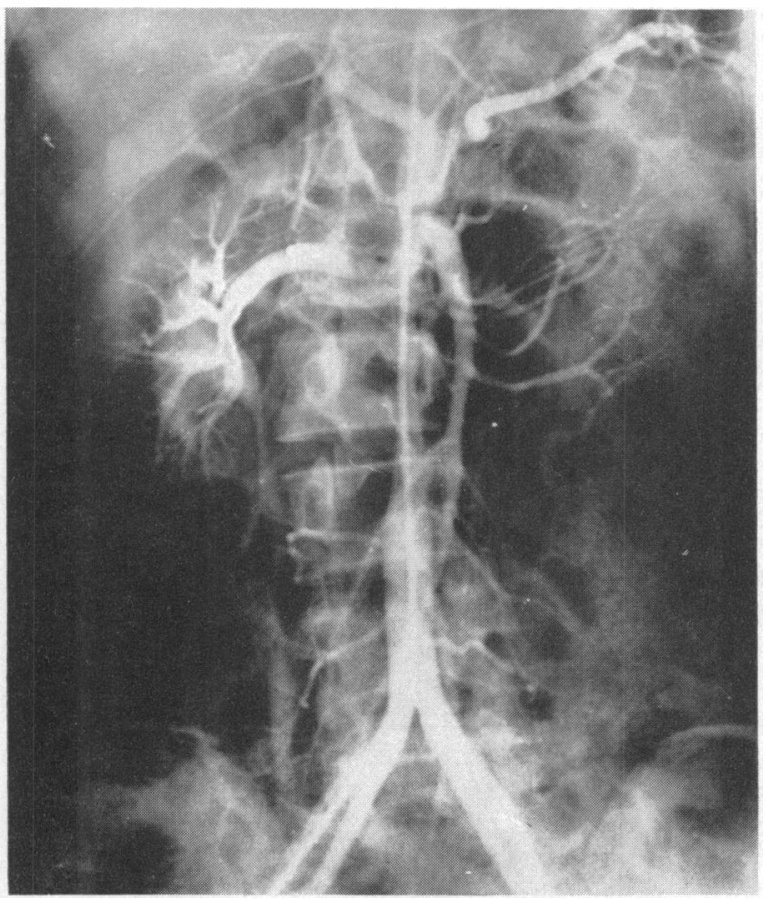

FIG. 9.-Case 7. Aortogram showing stenosis of segment of abdominal aorta below origin of right renal artery.
The left kidney weighed 115 g.: the capsule stripped easily leaving a smooth surface. There was clear demarcation of medulla and cortex which was $0.5 \mathrm{~cm}$. wide. Microscopical examination of the kidney showed no abnormality, except for a few lymphocytic aggregates in the interstitium. The renal artery was normal.

Case 8. A Chinese girl, aged 18, was apparently well until 12 days before admission when she suffered an attack of severe breathlessness which improved with treatment. She then became breathless on exertion and was admitted to hospital on July 14, 1960 in heart failure. All peripheral arterial pulses were easily felt, but the carotids were forceful and the left radial pulse was weaker than the right. The blood pressure reading in the right arm was $150 / 60$, in the left arm 120/100, and in the lower limbs $180 / 70 \mathrm{~mm}$. Hg. A forceful and displaced apex beat was felt. On auscultation, triple rhythm was noted, and along the left border of the sternum an early diastolic murmur of slight intensity was heard. A systolic bruit was heard over the epigastrium to the right of the midline. A few crepitations were heard over the bases of both lungs and the liver was enlarged to one finger's breadth below the costal margin.

Examination of the fundi revealed a mild degree of spasm of the arteries. She improved on treatment of the cardiac failure.

The hæmoglobin level was $10.4 \mathrm{~g} . / 100 \mathrm{ml}$. and both total white cell and differential counts were normal. The erythrocyte sedimentation rate was $25 \mathrm{~mm}$. in one hour. The Kahn test was negative. There was evidence of left ventricular hypertrophy on electrocardiographic examination. A radiograph of the chest showed a large heart with a prominent left ventricle. On intravenous pyelography, there was normal excretion by both kidneys, but better visualization of the right kidney which was smaller than the left. Aortography revealed a slightly dilated ascending aorta with a moderate degree of regurgitation of dye into the left ventricle. The innominate artery was dilated and irregular in outline and the left subclavian artery was narrowed at its origin; the right subclavian was not visible. The calibre of the descending thoracic and upper part of the abdominal aorta was grossly irregular with areas of narrowing and dilatation. There was stenosis of the right renal artery with post-stenotic dilatation and the nephrograms confirmed the difference in size of the kidneys. The patient was transferred to another hospital where she died in November 1960 in congestive heart failure.

Case 9. An Indian women, aged 32, was admitted on September 2, 1960 for breathlessness on effort of ten days' duration. She was in cardiac failure. All the peripheral pulses were felt, but those in the left 
upper limb were feeble. The blood pressure was $200 / 130 \mathrm{~mm}$. $\mathrm{Hg}$ in the right arm, and 170/100 $\mathrm{mm}$. $\mathrm{Hg}$ in the left. The heart was slightly enlarged, and there was triple rhythm but no murmurs. On auscultation over the abdomen, a soft systolic bruit was heard above and to the left of the umbilicus. The hæmoglobin level was $10.7 \mathrm{~g} . / 100 \mathrm{ml}$. and total white cell and differential counts were normal. The erythrocyte sedimentation rate was $13 \mathrm{~mm}$. at the end of one hour, and the Kahn test was negative. The electrocardiogram showed no abnormality. Radiological examination confirmed the slight cardiac enlargement. No abnormality was noted following intravenous pyelography. Aortography showed a normal aortic arch and branches, but there was obstruction to the flow of dye in the left and right subclavian arteries about $3 \mathrm{~cm}$. and $2 \mathrm{~cm}$. respectively from their origins. The right renal artery was normal, but there were two arteries on the left side, the upper and larger one being narrowed at its origin from the abdominal aorta. The segment of aorta at the level of the renal arteries was of irregular calibre. The left kidney was slightly smaller than the right.

The patient responded satisfactorily to treatment for cardiac failure, but later refused operation. She has been observed over the past year and her response to hypotensive drugs has not been satisfactory. Pulses in both upper limbs are now feeble as are the carotids, but the femoral pulses remain forceful.

\section{DisCUSSION}

The clinical presentation in this series was one of cardiac failure, encephalopathy, or cerebral hæmorrhage resulting from hypertension. In three patients the cause of the hypertension was established at necropsy and was due to renal ischæmia consequent on stenosis of one or both renal artery orifices, producing in effect a clinical equivalent of the Goldblatt clamp. The primary lesion, however, was in the aorta and consisted of a panarteritis affecting various segments and the proximal portions of branches arising from such segments. The orifices of these arteries were narrowed by thickened intima or occluded by thrombi resulting in reduced blood supply to the dependent organ or limb. In addition to the renal arteries, other visceral branches such as the right coronary, cœliac, and superior mesenteric, and all the large branches, including the common iliac, were affected. Localized dilatations of the abdominal aorta and right common iliac artery at the site of the lesions were present in Case 1, and irregular dilatations of the descending thoracic aorta and innominate artery were noted in Case 3. The aortic wall between the affected areas appeared normal and atheroma did not complicate the pathological changes. However, it is possible that the arteritis could have spread to involve the entire aorta were it not for the early death of these patients from the effects of hypertension.

The histological changes, which were similar in the three cases, were confined to the aorta and proximal portions of affected branches. The adventitia was thickened, with formation of some new vessels and infiltration by lymphocytes and plasma cells, mainly perivascular in distribution: many of the vasa vasorum showed marked endothelial proliferation with almost complete obliteration of the lumen. The characteristic change in the media was a gross destruction of elastic fibres resulting in their complete absence in some areas with localized dilatation of the wall: sharply demarcated areas of coagulative necrosis surrounded by round cells were also present. In addition, there was increased vascularization, some lymphocytic infiltration, and a few giant cells. The intima was grossly thickened with thrombi at certain sites, and in one area calcification was present in the deeper parts. The segmental distribution of the lesions in the aorta, the sharply demarcated areas of coagulative necrosis in the media resembling small infarcts, and the endarteritis of the vasa vasorum resulting in occlusion of their lumen, all suggest that the necrotic changes in the media result from obstruction to its blood supply. The intimal hyperplasia with thrombosis is probably secondary to the changes in the media.

The naked eye appearance of the lesions and their histological picture closely conformed to descriptions of lesions in the aortic arch and its branches seen in classical Takayashu's syndrome. Although the histological appearance of the aortic lesions was somewhat similar to that seen in syphilis, and to what has been reported in some cases of ankylosing spondylitis (Clark, Kulka, and Bauer, 1957) and giant-cell temporal arteritis (Cardell and Hanley, 1951), there was no other evidence 
of these diseases, either clinically or at necropsy: in addition, naked eye appearance of the aorta did not resemble syphilis, and the serological test was negative in these cases. No organisms were seen in the lesions to suggest an infective process.

Evidence obtained at necropsy from these and other reported cases indicates that any part of the aorta may be involved with resultant diversity of the clinical picture. When the ascending aorta is affected, occlusion of the orifice of a coronary artery may occur with consequent myocardial infarction (Barker and Edwards, 1955). Involvement of the aortic arch results in brachiocephalic manifestations, the classical Takayashu syndrome. Narrowing of the lumen of the thoracic aorta gives rise to absent pulses in the lower extremities and a clinical picture suggestive of coarctation of the aorta (Correa and Araújo, 1958; Isaacson et al., 1959). The abdominal aorta may be affected resulting in stenosis of one or both renal artery orifices and hypertension (Cases 1 to 3; Danaraj and Wong, 1959; Isaacson, 1961). Mesenteric artery occlusion may cause abdominal pain. The lower part of the abdominal aorta or its bifurcation may be involved giving rise to absent femoral pulses on one (Case 1) or both sides. In all these patients the underlying lesion was a panarteritis, presenting a similar microscopical appearance. Based on these clinico-pathological reports, the concept of primary arteritis of the aorta should be enlarged to include not only the early-recognized brachiocephalic syndrome, but other modes of presentation depending on which segments of the aorta are affected.

Renal artery involvement was demonstrated in aortograms in six patients (Cases 4 to 9). Five of these patients had weak or absent pulses in one or more limbs, and aortography revealed irregularity of the aortic calibre with narrowing or occlusion of one or more of its branches, in addition to stenosis of a renal artery. The only arterial involvement that could be detected in the remaining patient (Case 7) when first seen was left renal artery stenosis. Following nephrectomy, her blood pressure returned to normal, but a year later the femoral pulses became weak, and constriction of a long segment of the aorta below the origin of the renal arteries was seen in an aortogram. It seems likely that the primary disease process in these patients is in the aorta, and is similar to that found in the patients who come to necropsy.

On the basis of clinical, radiological, and pathological evidence, this group of nine patients constitutes a single clinico-pathological entity resembling what has been described as Takayashu's syndrome except that other segments of the aorta besides the aortic arch were also affected. Although narrowing of the arterial lumen typifies the lesion, localized dilatation of the affected arteries may occur as was noted in Cases 1 and 3 post mortem. Several areas of ectasia were described in the case reported by Cosma et al. (1959) and in the first case of Isaacson's series (1961). Furthermore, dilatation involving the aorta at its origin may result in aortic regurgitation as seen in Case 8 and as reported by Jervell (1954).

The disease runs a chronic and progressive course, increasing involvement of the aorta being indicated by weakening or absence of pulses that were previously present (Cases $4,5,7$, and 9), or the development of murmurs over the aorta (Cases 5 and 7). Intravenous pyelography is an important preliminary investigation in patients presenting with hypertension and may reveal differences in kidney size (Hodson, 1957) or irregularity of the ureter caused by enlarged collateral ureteric arteries to the ischæmic kidney (Case 4; Thomas and Levin, 1961). However, aortography is essential in establishing the extent of the aortic lesion, the diagnosis of renal artery stenosis, the involvement of other branches, and the existence of collateral circulation. When the large branches to the head and limbs are occluded, the development of collateral circulation enables the patient to survive for several years. With involvement of renal arteries, however, prognosis immediately becomes serious because resultant hypertension is severe and leads to premature death.

Various workers (Poutasse, 1956; DeCamp and Birchall, 1958; Morris et al., 1960) have shown that hypertension secondary to occlusive lesions of the renal artery may be successfully treated by nephrectomy or by vascular reconstructive procedures. In the three patients who were subjected to nephrectomy, the blood pressure returned to normal in two, but remained high in the third (Case 6) probably because of ischæmia of the remaining kidney from concomitant stenosis of its artery. 
The removal of a kidney is a simpler and less hazardous operation than procedures to restore adequate renal blood flow, but in circumstances such as these, where the primary lesion is in the aorta and may progress to involve both renal arteries, some form of arterial reconstruction is to be preferred.

The ætiology of the condition remains obscure. Laboratory investigations did not show any consistent abnormality except for a raised erythrocyte sedimentation rate and a mild anæmia. The Kahn test for syphilis was negative and no L.E. cells were found in the peripheral blood. Tuberculous lymphadenitis was present in one patient (Case 5) in this series, and pulmonary tuberculosis in another patient reported earlier as a case of obliterative brachiocephalic arteritis (Danaraj and Wong, 1960). One patient in the Japanese series (as reviewed by Caccamise and Whitman, 1952) had active pulmonary tuberculosis. In view of the high prevalence of tuberculosis both in Japan and Singapore this association is probably coincidental.

\section{SUMMARY}

The evidence presented by the nine cases described in this paper indicates that primary arteritis of the aorta is a single clinico-pathological entity of which Takayashu's syndrome is a part. Different segments of the aorta may be affected resulting in a variety of symptom complexes. In this series, the mode of presentation was hypertension consequent on renal artery stenosis. Early diagnosis is important and surgical treatment is indicated to relieve the hypertension which carries an immediately serious prognosis.

We are indebted to Professor Yeoh Ghim Seng and Mr. Yong Nen Khiong for the surgical treatment of Cases 5 , 6, and 7; to Dr. Tock Peng Chong for performing the necropsy on Case 3; and to Mr. V. Nalpon and Mr. Ho Tat Seng for the photographs.

\section{REFERENCES}

Ask-Upmark, E. (1954). Acta med. scand., 149, 161.

Barker, N. W., and Edwards, J. E. (1955). Circulation, 11, 486.

Caccamise, W. C., and Whitman, J. F. (1952). Amer. Heart J., 44, 629.

Caldwell, R. A., and Skipper, E. W. (1961). Brit. Heart J., 23, 53.

Cardell, B. S., and Hanley, T. (1951). J. Path. Bact., 63, 587.

Clark, W. S., Kulka, J. P., and Bauer, W. (1957). Amer. J. Med., 22, 580.

Correa, P., and Araújo, J. (1958). Amer. J. clin. Path., 29, 560.

Cosma, J., Maruyama, Y., Pettet, J. R., and Cutshall, V. (1959). Circulation, 20, 267.

Danaraj, T. J., and Wong, H. O. (1959). Circulation, 20, 856. (1960). Amer. J. Cardiol., 5, 277.

DeCamp, P. T., and Birchall, R. (1958). Surgery, 43, 134.

Frövig, A. G., and Löken, A. C. (1951). Acta psychiat. scand., 26, 313.

Gibbons, T. B., and King, R. L. (1957). Circulation, 15, 845.

Giffin, H. M. (1939). Proc. Mayo Clin., 14, 561.

Hodson, C. J. (1957). Proc. roy. Soc. Med., 50, 539.

Isaacson, C. (1961). J. Path. Bact., 81, 69.

- Klachko, D. M., Wayburne, S., and Simson, I. W. (1959). Lancet, 2, 542.

Jervell, A. (1954). Amer. Heart J., 47, 780.

Kalmansohn, R. B., and Kalmansohn, R. W. (1957). Circulation, 15, 237.

Koszewski, B. J. (1958). Angiology, 9, 180.

Lessof, M. (1958). Guy's Hosp. Rep., 107, 53.

Lewis, T., and Stokes, J. (1942). Brit. Heart J., 4, 57.

Morris, G. C. Jr., De Bakey, M. E., Cooley, D. A., and Crawford, E. S. (1960). Ann. Surg., $151,854$.

Poutasse, E. F. (1956). Circulation, 13, 37.

Ross, R. S., and McKusick, V. A. (1953). Arch. intern. Med., 92, 701.

Savory, W. S. (1856). Med.-chir. Trans., 39, 205.

Shimizu, K., and Sano, K. (1951). J. Neuropath. clin. Neurol., 1, 37.

Skipper, E., and Flint, F. J. (1952). Brit. med. J., 2, 9.

Takayashu, M. (1908). Acta Soc. Ophthal. Jap., 12, 554

Thomas, R. G., and Levin, N. W. (1961). Brit. J. Radiol., 34, 438.

Trias de Bes, L., Lucas, J. G. S., and Barcons, F. B. (1955). Brit. Heart J., 17, 484. 